\title{
Economia criativa: uma visão global
}

\section{Alessandra Meleiro*}

Fábio Fonseca*

Resumo: A economia criativa tem sido compreendida como uma potencial alavanca para o desenvolvimento de muitas nações, sendo que mais de 60 países já realizam procedimentos sistemáticos de mapeamento do seu setor criativo. Em estágio mais amadurecido encontram-se os países desenvolvidos, notadamente os Estados Unidos, as principais economias européias - com destaque para o Reino Unido - e a Austrália. Porém, mesmo estes ainda vislumbram as perspectivas de expansão do setor, inserindo o tema estrategicamente com papel de destaque em suas agendas econômicas. Países emergentes e em desenvolvimento conseguem ter participações expressivas em áreas específicas. Porém há um vasto território inexplorado de possibilidades, que devem ser objeto de políticas públicas, concebidas e implementadas num ambiente de cooperação internacional, especialmente a chamada Cooperação Sul-Sul.

Palavras Chave: Economia criativa; cadeias produtivas; cidades criativas

Abstract: The creative economy has been understood as a potential lever for the development of many nations, and more than 60 countries already conduct systematic procedures mapping of its creative sector. In more mature stage are developed countries, notably the United States, major European economies particularly the UK - and Australia. But even these still envision the future growth of the industry by entering the topic with strategically important role in their economic agendas. Emerging and developing countries manage to have significant holdings in specific areas. But there is a vast uncharted territory of possibilities, which must be the object of public policy, designed and implemented in an environment of international cooperation, especially the so-called South-South Cooperation.

Key-words: Creative economy, production chains, creative cities.

\footnotetext{
* Professora Adjunta do curso de produção cultural da Universidade Federal Fluminense (UFF) e pesquisadora associada do Centro Brasileiro de Análise e Planejamento (CEBRAP).

* Professor da Universidade Estadual do Rio de Janeiro (UERJ) e Université François Rabelais
}

Latitude, vol. 6, n², pp.06-21, 2012

DOI: https://doi.org/10.28998/2179-5428.20120209 
Economia criativa: uma visão global

\section{Uma visão global}

O mercado global de bens e serviços oriundos da economia criativa tem experimentado, nos últimos anos, um crescimento sem precedentes ${ }^{1}$. O valor das exportações anuais desse segmento alcançou US\$ 592 bilhões, em 2008, o que representa um crescimento médio anual de $14 \%$ no período de 2002-2008. Segundo a UNCTAD, as indústrias criativas são um dos setores mais dinâmicos do comércio internacional e a demanda global para os produtos criativos continuou crescendo, apesar da crise financeira e da recessão global de 2008. De acordo com a UNESCO ${ }^{2}$, o comércio de bens criativos aumentou de US\$ 205 para US\$ 407 bilhões em 2008, com crescimento médio de $11.5 \%$, no período $2002-2008$, praticamente dobrando de valor em seis anos.

A economia criativa tem sido compreendida como uma potencial alavanca para o desenvolvimento de muitas nações, sendo que mais de 60 países já realizam procedimentos sistemáticos de mapeamento do seu setor criativo ${ }^{3}$. Em estágio mais amadurecido, encontram-se os países desenvolvidos, notadamente os Estados Unidos, as principais economias europeias - com destaque para o Reino Unido - e a Austrália. Porém, mesmo estes ainda vislumbram as perspectivas de expansão do setor, inserindo o tema estrategicamente com papel de destaque em suas agendas econômicas. Países emergentes e em desenvolvimento conseguem ter participações expressivas em áreas específicas. Porém há um vasto território inexplorado de possibilidades, que devem ser objeto de políticas públicas, concebidas e implementadas num ambiente de cooperação internacional, especialmente a chamada Cooperação Sul-Sul.

Muitos fatores contribuíram para a formação de um cenário favorável à chamada sociedade do conhecimento, onde a economia criativa encontra solo fértil: (a) o fenômeno China, cuja capacidade de produção industrial se impõe implacavelmente diante de todo o planeta, esvaziando ou mesmo inviabilizando a indústria de base tradicional de muitos países, até mesmo países desenvolvidos; (b) o desenvolvimento tecnológico, notadamente o das tecnologias de comunicação,

\footnotetext{
${ }^{1}$ UNCTAD - United Nations Conference on Trade and Development (2008) The Creative Economy Report (página 106) [http://www.unctad.org/en/docs/ditc20082cer_en.pdf] 2 UIS UNESCO Institute for Statistics - International Flows of Selected Cultural Goods and Services, 1994-2003 - Defining and Capturing the Flows of Global Cultural Trade (Montreal, 2005) (página 9) [http://www.uis.unesco.org/template/pdf/cscl/IntlFlows_EN.pdf] ${ }^{3} \mathrm{Pol}, \mathrm{H}$. van der - UIS - UNESCO Institute for Statistics - Measurement Issues in Relation to Cultural Statistics (Istanbul, 2007)

[http://www2.dpt.gov.tr/oecd_ing/topkapi_a/29June2007/9.00-10.30/Hendrik\%20pol_Istanbul-2007_2.ppt]
} 
Alessandra Meleiro

Fábio Fonseca

com destaque para a internet, que promove distribuição democrática de informação, diminuindo as distâncias globais, inclusive mitigando barreiras culturais; (c) a inserção definitiva do meio ambiente na agenda internacional, promovendo a conscientização para o desenvolvimento sustentável, a partir de mudanças de paradigmas de desenvolvimento.

A esses fatores, adiciona-se o respaldo proporcionado por marcos regulatórios internacionais. O principal deles é o Acordo sobre Aspectos dos Direitos de Propriedade Intelectual Relacionado ao Comércio, mais conhecido como Acordo TRIPS4. Ele dispõe sobre a aplicabilidade dos princípios básicos do GATT $^{5}$ e dos acordos internacionais sobre propriedade intelectual; estabelece os parâmetros gerais sobre os direitos de propriedade intelectual considerados adequados; prevê medidas para fazer cumprir aqueles direitos; e cria mecanismos para a solução multilateral de controvérsias. Ainda que não haja unanimidade dos países em torno do documento, é inegável que se constitui numa base regulatória que pavimenta a estrada para a circulação de bens de natureza intelectual.

\subsection{União Europeia}

A União Europeia tem dedicado um expressivo espaço ao tema, sendo que congrega agências de desenvolvimento do setor criativo de praticamente todos os seus afiliados. Entre estes, são realizados dezenas de eventos anuais, entre seminários, congressos, workshops etc., relacionados ao setor. Além destas, outras tantas agências culturais e conselhos de arte e patrimônio histórico e cultural se voltam para a economia criativa. Em 2006, foi publicado o relatório The Economy of Culture in Europe ${ }^{6}$, provavelmente o estudo mais denso já realizado neste campo. Segundo o documento, a economia da cultura era responsável por $2,6 \%$ do PIB regional e $3,1 \%$ dos postos de trabalho nos 25 países que compunham a Comunidade Europeia. Para se ter uma idéia da dimensão dessa contribuição, a produção de químicos, borracha e plástico (componentes essenciais da indústria de base) contribui com $2,3 \%$ e a produção de alimentos, bebidas e fumo participa com $1,9 \%$ do PIB macrorregional 7 . A pesquisa está sendo atualizada, com inclusão dos novos membros da comunidade.

Tabela 1.

\footnotetext{
4 Trade-Related Aspects of Intellectual Property Rights

${ }^{5}$ General Agreement on Tariffs and Trade

${ }^{6}$ http://www.keanet.eu/ecoculture/studynew.pdf

${ }^{7}$ Gorgulho, L. F., Goldenstein, M., Machado Alexandre, P. V., Taboas de Mello, G. A. - A Economia da Cultura, o BNDES e o Desenvolvimento Sustentável (página 308) [http://www.bndes.gov.br/SiteBNDES/export/sites/default/bndes_pt/Galerias/Arquivos/con hecimento/bnset/set3007.pdf]
} 
Economia criativa: uma visão global

Participação dos Setores Culturais e Criativos nos PIBs de Países Europeus Selecionados

\begin{tabular}{lccccc}
\hline PAÍSES / SETORES & ALEMANHA & ESPANHA & FRANÇA & REINO UNIDO & ITÁLIA \\
\hline & & & & & \\
\hline Culturais e Criativos & $\mathbf{2 , 5}$ & $\mathbf{2 , 3}$ & $\mathbf{3 , 0}$ & $\mathbf{3 , 4}$ & $\mathbf{2 , 3}$ \\
\hline Alimentos, Bebidas e Fumo & 1,6 & 2,2 & 1,9 & 1,9 & 1,5 \\
Têxtil e Confecç̃oes & 0,3 & 0,7 & 0,4 & 0,4 & 1,3 \\
Químicos e Fibras Sintéticas & 1,9 & 1,3 & 1,6 & 1,4 & 1,2 \\
Máquinas e Equipamentos & 2,8 & 1,0 & 1,0 & 1,0 & 2,1 \\
Computadores e Bens Relacionados & 1,4 & 2,3 & 1,3 & 2,7 & 1,2 \\
Imobiliário & 2,6 & 3,0 & 1,8 & 2,1 & 1,0
\end{tabular}

Fonte: Eurostat e Amadeus - The Economy of Culture in Europe, Comissão Européia (2006)

O Creative Economy Report, trabalho de pesquisa organizado pela UNCTAD e pelo PNUD, foi lançado durante a XII Conferência da UNCTAD, realizada em Accra (Gana), em abril de 2008. O documento, que contém um mapeamento do cenário global da economia criativa, aponta alguns dados impressionantes sobre o crescimento dessa economia no velho continente:

The so-called 'creative cities' are proliferating in Europe and North America, revitalizing the economy of urban centres through cultural and social developments offering attractive Jobs, particularly to young people. The turnover of the European creative industries amounted to 654 billion euros in 2003, growing 12.3 per cent faster than the overall economy of the European Union and employing over 5.6 million people. ${ }^{8}$

8 UNCTAD (2008) The Creative Economy Report (página 5) [http://www.unctad.org/en/docs/ditc20082cer_en.pdf] 
Alessandra Meleiro

Fábio Fonseca

\subsection{Reino Unido - Um Caso Especial}

O Reino Unido foi provavelmente quem mais cedo se mobilizou em prol do setor e, por iniciativa pioneira do Labour Party, incluiu a economia criativa em sua plataforma política visando às eleições de 1997. Não apenas incluiu o tema no programa como efetivamente o levou a termo. Lá, onde existe um ministério dedicado ao tema ${ }^{9}$, o crescimento médio das indústrias criativas foi de $5 \%$ ao ano, superior aos 3\% do restante da economia. Segundo a UNCTAD ${ }^{10}$,

Employment growth was also substantial. In the United Kingdom, employment grew approximately twice as fast in the creative sector as elsewhere over the last decade, while in the cultural sector of Europe as a whole, the average number of employed persons grew about 3 to 5 per cent annually in the period from 1995 to 2000, with significantly higher rates of growth in some countries, pointing again to generally stronger employment growth in the creative industries than elsewhere in the economy.

Trata-se de uma extraordinária experiência de mobilização da sociedade civil, capitaneada pelo poder público. Foi formada uma rede sólida envolvendo o estado, a universidade, agentes financeiros, empresários, empreendedores e profissionais criativos, em torno da qual se construiu uma estrutura de incentivo ao fortalecimento dessa economia. Como resultado, vemos o "boom" do cinema britânico, o sucesso de seus incontáveis festivais, potencializando o turismo, a presença forte de seus músicos na cena internacional, o fabuloso desenvolvimento no campo de design e da arquitetura, o vigor sem precedentes do seu mercado editorial ${ }^{11}$, entre diversas outras áreas.

É notável o processo de regeneração urbana e de desenvolvimento de várias cidades que apostaram e investiram no setor, principalmente aquelas que sofreram

\footnotetext{
${ }^{9}$ Ministry For Creative Industries and Tourism

10 UNCTAD (2008) The Creative Economy Report (página 29) [http://www.unctad.org/en/docs/ditc20082cer_en.pdf]

11 De acordo com o estudo "International Measurement of the Economic and Social Importance of Culture", realizado por John C. Gordon e Helen Beilby-Orrin para a Organização para a Cooperação e o Desenvolvimento Econômico (OCDE), em 2003, o mercado editorial do Reino Unido era estimado em 8,6 bilhões de libras esterlinas, contribuindo com 1,2 \% do PIB. [http://www.oecd.org/dataoecd/26/51/37257281.pdf]
} 
Economia criativa: uma visão global

o esvaziamento econômico pela perda de competitividade para a indústria chinesa. Cidades como Manchester, Liverpool, Sheffield, Halifax, Barnsley, Huddersfield, entre outras, são exemplos impressionantes desse fenômeno. Elas se reinventaram e, como consequência, estão sendo redescobertas. É comum a todas elas a existência de um edifício dedicado ao abrigo de agências de desenvolvimento local de indústrias criativas, comportando atividades de pesquisa, financiamento, fomento, treinamento e formação de profissionais em diversas áreas e incubação de negócios. Os espaços contam ainda com uma estrutura aberta ao público em geral para a fruição de obras de arte, cinema, teatro e café, com uma agradável atmosfera de cultura e entretenimento. O edifício pode ser uma indústria desativada, cujas instalações passaram por uma profunda renovação e adaptação para o novo programa arquitetônico; pode ser uma arquitetura nova, moderna e conceitualmente arrojada; ou, ainda, uma fusão entre as duas primeiras situações. O fato é que tais edifícios - os Iconic Buildings, como são chamados pelos britânicos - trazem concretude ao conceito de economia criativa, pois são acessíveis e frequentados pela população, aumentando o nível de adesão local a esse processo de reinvenção econômica.

Nesses ambientes convivem artistas plásticos, músicos, escritores, desenvolvedores de games e softwares, videomakers, designers, diretores de cinema e teatro, produtores culturais e empreendedores criativos, em geral. E não apenas esses, mas também outros atores importantes da cadeia econômica, tais como empresários e agentes de financiamento. É muito interessante considerar que tais locais são, ao mesmo tempo, pontos de convergência, uma vez que seu forte valor de referência atrai os indivíduos alinhados ao processo criativo, e de irradiação, pois dali resultam produtos, projetos, atividades etc., que se espalham por toda a cidade.

A capital inglesa, Londres, é o maior exemplo desse processo: as indústrias criativas representam o segundo maior setor na economia londrina, empregando diretamente mais de 500 mil pessoas $^{12}$. Entre 1995 e 2001, o setor cresceu mais rapidamente do que qualquer outro, à exceção do tradicional setor financeiro e de negócios, contabilizando entre $20 \%$ e $25 \%$ do crescimento do emprego neste período ${ }^{13}$.

\footnotetext{
${ }^{12}$ Organização para a Cooperação e o Desenvolvimento Econômico (OCDE) - International Measurement of the Economic and Social Importance of Culture (página 7) [http://www.oecd.org/officialdocuments/displaydocumentpdf?cote=STD/NAFS(2007)1\&doc language $=$ en]

${ }^{13}$ GLA Economics (2004) London's Creative Sector: 2004 Update (Executive Summary) [http://www.planotecnologico.pt/document//ondon_creative_sector_2004.pdf]
} 
Alessandra Meleiro

Fábio Fonseca

Tabela 1. OCDE - Estimativas de Emprego Cultural em Algumas Cidades

\begin{tabular}{|c|c|c|c|c|c|}
\hline Cidade & $\begin{array}{r}\text { Ano } \\
\text { Referência } \\
\end{array}$ & $\begin{array}{l}\quad \text { Pop } \\
\text { ulação } \\
\text { (milhões) }\end{array}$ & \begin{tabular}{|l}
\multicolumn{2}{c}{ Populaçã } \\
o da Cidade em \\
relação à \\
População \\
Nacional (\%)
\end{tabular} & $\begin{array}{l}\text { Empre } \\
\text { go na cidade } \\
\text { na área de } \\
\text { cultura } \\
(x 1.000)\end{array}$ & $\begin{array}{l}\text { Participaçã } \\
\text { o da Cidade no } \\
\text { emprego na área } \\
\text { cultural Nacional } \\
(\%)\end{array}$ \\
\hline Londre & 2002 & 7.37 & 12.4 & 525 & 23.8 \\
\hline al Montre & 2003 & 2.37 & 7.4 & 98 & 16.4 \\
\hline Iorque $^{\text {Nova }}$ & 2002 & 8.10 & 2.8 & 309 & 8.9 \\
\hline Paris & 2003 & 11.1 & 18.5 & 113 & 45.4 \\
\hline
\end{tabular}

Fonte: OCDE - International Measurement of the Economic and Social Importance of Culture

\subsection{Cidades Criativas}

Um aspecto importante a ser considerado é que parece haver um entendimento consolidado em todo o mundo de que é o ambiente urbano o mais propício ao desenvolvimento da economia criativa, seja pelo perfil multiétnico, pela convivência ativa de diferentes grupos e comunidades, pela convergência de culturas e saberes oriundos de outras áreas nacionais, pela maior disponibilidade de tecnologias, entre outros fatores que não se fazem presentes expressivamente em ambientes rurais.

Desde 2004, a UNESCO promove a rede Cidades Criativas, que congrega cidades de diversas regiões que se integram num processo de intercâmbio, troca de experiências e difusão de melhores práticas, com vistas ao desenvolvimento pela conversão de seus potenciais criativos em promoção econômica. Elas estão inseridas em sete categorias préestabelecidas, as quais servem para melhor estabelecer os focos de atenção para seus esforços. De maneira surpreendente, não figura ainda na lista da UNESCO ${ }^{14}$ a cidade de Londres, cuja economia criativa emprega um em cada cinco trabalhadores londrinos e responde por impressionantes $£ 11,4$ bilhões de contribuição para a balança comercial do Reino Unido, razão pela qual o governo pretende transformá-la no centro criativo do

${ }^{14}$ Cabe ressaltar que a inserção de uma cidade na Rede Cidades Criativas, da UNESCO, depende de iniciativa da própria cidade, a qual deve obedecer alguns critérios para a sua aceitação. 
Economia criativa: uma visão global

mundo. Outra ausência notável é a de Amsterdã. As indústrias criativas empregam $7 \%$ dos trabalhadores e representam $4,5 \%$ do PIB da capital holandesa. ${ }^{15}$

Tabela 2. Rede cidades criativas

\begin{tabular}{|c|c|c|}
\hline CATEGORIA & CIDADE & PAÍS \\
\hline \multirow[t]{4}{*}{ Literatura } & Edinburgo & Reino Unido \\
\hline & Iowa City & Estados Unidos \\
\hline & Melbourne & Austrália \\
\hline & Dublin & Irlanda \\
\hline Cinema & Bradford & Reino Unido \\
\hline \multirow[t]{4}{*}{ Música } & Bolonha & Itália \\
\hline & Ghent & Bélgica \\
\hline & Glasgow & Reino Unido \\
\hline & Sevilha & Espanha \\
\hline Artesanato e Folclore & Aswan & Egito \\
\hline \multirow{11}{*}{ Design } & Kanazawa & Japão \\
\hline & Santa Fé & Estados Unidos \\
\hline & Icheon & Coréia \\
\hline & Berlin & Alemanha \\
\hline & Buenos Aires & Argentina \\
\hline & Kobe & Japão \\
\hline & Montreal & Canadá \\
\hline & Nagoya & Japão \\
\hline & Shenzhen & China \\
\hline & Seul & Coréia \\
\hline & Shangai & China \\
\hline Arte Mídia & Lyon & França \\
\hline \multirow[t]{3}{*}{ Gastronomia } & Popayan & Colômbia \\
\hline & Chengdu & China \\
\hline & Östersund & Suécia \\
\hline
\end{tabular}

Fonte: UNESCO

15 Santos-Duisenberg, E. dos, em Economia Criativa: Uma Opção de Desenvolvimento Viável?, inserido em Fonseca Reis, A. C. (organização) (2008) Economia Criativa Como Estratégia de Desenvolvimento: Uma Visão dos Países em Desenvolvimento (São Paulo: Editora Itaú Cultural) (página 64) 
Alessandra Meleiro

Fábio Fonseca

\subsection{América Latina}

A economia criativa na América Latina vem conquistando espaço dentro das suas políticas públicas, dada a crescente compreensão de seu potencial para o desenvolvimento econômico e social. Entidades como o Convênio Andrés Bello, a Organização dos Estados Americanos (OEA), A Organização dos Estados Iberoamericanos para a Educação, a Ciência e a Cultura (OEI), o Centro Regional para a Promoção de Livros na América Latina e no Caribe (CERLALC), o PNUD, A UNESCO e a UNCTAD desenvolvem uma série de estudos visando subsidiar programas públicos de desenvolvimento desta economia. Alguns desses estudos mostram que gradualmente vem crescendo a oferta de dados estatísticos do segmento na região, como consequência de uma maior determinação política dos governos em promover iniciativas no setor. As economias mais desenvolvidas, como Brasil, Argentina, México, Colômbia e Chile, têm concentrado os maiores esforços nos últimos anos, o que vem, pouco a pouco, se espalhando para os países vizinhos.

A Argentina tem protagonizado um grande incremento de sua indústria do cinema e audiovisual, onde também se inclui a produção publicitária, adotando uma estratégia que tem se mostrado vitoriosa, que contempla o fomento da produção nacional a partir de uma taxa para exibição de produções estrangeiras, com intermediação técnica do INCAA - Instituto Nacional de Cine y Artes Audiovisuales -, instituição amplamente legitimada pela comunidade cinematográfica local. Não por acaso, a cinematografia e, de modo geral, a indústria do cinema e audiovisual da Argentina atualmente é respeitada em todo o mundo, sendo reconhecida por muitos como a mais importante da América Latina. Sob a condução do Ministério da Cultura da Argentina está em marcha o desenvolvimento do SICSUR - Sistema de Informações Culturais do MERCOSUL -, que visa à construção de um framework estatístico comum e à disponibilização de dados da economia cultural da Argentina, da Bolívia, do Brasil, do Chile, da Colômbia, do Equador, do Paraguai, do Peru e da Venezuela ${ }^{16}$. Ainda, neste sentido, cabe lembrar a participação de Buenos Aires na rede Cidades Criativas, da UNESCO, como cidade do design, cujos esforços se voltam para a formação de profissionais em universidades e intercâmbios internacionais.

A Colômbia também tem envidado esforços no sentido de desenvolvimento da economia criativa. O Convênio Andrés Bello tem um papel decisivo, articulando uma rede de treinamento e difusão do setor, além do financiamento de

16 www.sicsur.org 
Economia criativa: uma visão global

projetos. A cidade de Popayan foi a primeira cidade gastronômica da rede Cidades Criativas, da UNESCO, oferecendo um modelo bastante inovador para o seu desenvolvimento, tendo apresentado grandes avanços no sentido de formalizar a sua indústria gastronômica informal. Seja pela facilitação de espaços e outras instalações, pelo estabelecimento de parâmetros obrigatórios de higiene e regulações cabíveis, e publicando e divulgando amplamente sua rede de restaurantes, incluindo os seus menores quiosques de alimentação, Popayan tem revigorado sua economia e aumentado a oferta de emprego e elevação da renda através do suporte a esse setor. A cidade insere-se, assim, num contexto internacional, onde pode compartilhar suas receitas, temperos e rituais. Trata-se de inegável avanço econômico com valorização cultural e elevação de autoestima dos cidadãos.

O México possui estudos recentes que apontam o crescimento da indústria cultural, medida por sua participação no PIB, atingindo $6,7 \%{ }^{17}$, credenciando o setor a uma condição de receber maior atenção das autoridades governamentais. Um programa governamental que vale mencionar nesse sentido é o E-CULTURA ${ }^{18}$, que promove uma rede de instituições e agentes culturais diversos em todo o território nacional, conectando-os digitalmente, de modo a proporcionar a integração, intercâmbio e disponibilização online de um impressionante conteúdo de livros e documentos. Além disso, o E-CULTURA focaliza a conexão entre os atores da economia cultural, cooperando diretamente para a comercialização de produtos e estabelecimentos de negócios no setor.

É ainda notável, no entanto, que os avanços do setor na América Latina tenham sido desiguais. Alguns dos países latino-americanos ainda não fazem medições formais desses impactos, principalmente no Caribe e na América Central, sendo exceções honrosas a Jamaica e a Guatemala. Outros já contam com sistemas de mensuração dessa economia, porém, as diferentes metodologias aplicadas, com níveis distintos de aprofundamento e refinamento, inviabilizam a conexão e o cruzamento de dados na região. Daí a grande contribuição que se espera do SICSUR, na construção de um framework comum, que permita a comunicação de informações para uma avaliação acurada de sua economia criativa. O Grupo de Estados da África, Caribe e Pacífico (ACP), entidade ligada à UNESCO, que congrega mais de 80 países, também tem trabalhado nesta direção. Em 2006, foi realizado o primeiro ACP FESTIVAL, em Santo Domingo, na República Dominicana, apresentando as mais diversas formas de manifestação culturais e de

\footnotetext{
17 Piedras, E., em México: Tecnologia e Cultura para um Desenvolvimento Integral, inserido em Fonseca Reis, A. C. (organização) (2008) Economia Criativa Como Estratégia de Desenvolvimento: Uma Visão dos Países em Desenvolvimento (São Paulo: Editora Itaú Cultural) (página 146)

${ }^{18} \mathrm{http}: / /$ www.ecultura.gob.mx
} 
Alessandra Meleiro

Fábio Fonseca

economia de lastro criativo no país, que foi precedido por uma reunião de ministros de cultura para a discussão do tema. Ainda é pouco, mas sem dúvida já é um apontamento significativo de que a questão ganha força nas agendas dos países da região. Veremos o Brasil adiante.

\section{5 África}

Vários países africanos criaram seus organismos nacionais dedicados à economia criativa, como Nigéria, Gana e Quênia. Em 2008, por ocasião da 12a Conferência das Nações Unidas para o Comércio e Desenvolvimento - a UNCTAD XII -, realizada em Gana, foi apresentado o Programa África Criativa, uma iniciativa conjunta entre o Programa das Indústrias Criativas da UNCTAD e a União Africana, visando ao estudo, mapeamento e fomento da economia criativa no continente; na mesma conferência, lançou-se o "Creative Economy Report", mapeamento do cenário global da economia criativa produzido conjuntamente pela UNCTAD e pelo PNUD, densamente enriquecido com dados estatísticos.

A África do Sul, país africano com maior inserção no cenário econômico internacional, tem desenvolvido uma política agressiva de redução das desigualdades entre populações negras e brancas, bem como entre suas regiões. Esse processo, que alguns economistas classificam como política de emparelhamento (ou o catching up), incluiu fortemente a economia criativa em sua estratégia de desenvolvimento. A Província de Gauteng, uma das mais importantes e densamente povoadas, tem uma secretaria específica cuidando do segmento e dirigindo projetos de qualificação profissional em áreas como moda e estilo, design, gastronomia, música, cinema e vídeo e turismo cultural.

Em 2003, uma reunião da ACP Group of States, realizada no Senegal, foi totalmente dedicada à economia criativa e resultou na elaboração conjunta do Dakar Plan of Action on the Promotion of ACP Cultures and Cultural Industries ${ }^{19}$, documento que alinhavou o compromisso dos países membros no sentido de construir uma plataforma para o seu crescimento econômico a partir do setor. O documento previa a cooperação na área de cultura, uma ação conjunta de formulação de políticas culturais regionais, políticas para a preservação do patrimônio cultural, a criação de mecanismos de apoio financeiro para empreendimentos criativos e a criação de uma força tarefa para diminuir o gap entre os países membros da ACP e os países desenvolvidos.

\section{6 Ásia / China}

${ }^{19} \mathrm{http}$ //ocpa.irmo.hr/resources/docs/Dakar_Plan_of_Action-en.pdf 
Economia criativa: uma visão global

São diversas as iniciativas encontradas na Ásia na área de economia criativa. Em 2005, foi realizado um simpósio em Nagaur, na Índia, organizado pela UNESCO, que tinha como objetivo discutir o papel das indústrias criativas e o desenvolvimento, visando especialmente à importância das atividades artísticas e culturais locais. As recomendações extraídas do simpósio, conhecidas como a Iniciativa Jodhpur, pôs em curso um planejamento para coleta de dados e plano de ações a serem implementados em vários países asiáticos.

Pesquisas recentes sugerem que as atividades inovadoras desenvolvidas naquele continente, particularmente em produção de serviços e indústrias criativas, estão mais fortemente concentradas em clusters de alta tecnologia, em cidades inseridas na economia global. O desenvolvimento de tais cidades é claramente influenciado pela atuação de empresas e governos, que também têm criado suas estruturas de ação. Neste sentido, podemos destacar a Índia, a Indonésia e a Malásia, que possuem ministérios e outros órgãos de interesse exclusivo em economia criativa e áreas correlatas.

Em 2009, realizou-se, na capital da Malásia, a Kuala Lumpur Design Week, contando com a participação de mais de 500 delegados de todo o mundo. Na ocasião, o presidente da KLDW'09, em seu discurso de abertura, proferiu a seguinte frase: "vamos nos unir e mostrar para o mundo o que temos; agora é a hora de brilhar como uma nova Malásia e seu novo poder de economia criativa". Essa citação expressa, em parte, o entusiasmo e espaço que o setor vem conquistando em diferentes partes do globo. A própria China, que detém espetacularmente a hegemonia da produção industrial de base tradicional, tem dedicado atenção ao setor. Em 2003, a China lançou um programa piloto envolvendo 35 organizações culturais de 9 províncias, visando à compreensão das possibilidades de fortalecimento dessa economia. Nesse sentido, foram lançados, nos últimos anos, quatro centros regionais de economia criativa, sendo dois deles sediados na região de Pequim e dois em Hong Kong. São eles: Daishanzi Art District (Factory 798) Pequim; Dahuan (Great Circle) - Pequim Jockey Club Creative Arts Centre - Hong Kong e West Kowloon Cultural District - Hong Kong.

O PNUD desempenhou um importante papel na viabilização desses centros, trabalhando em cooperação com autoridades chinesas na construção de sua arquitetura institucional. Fatos como esses mostram que as autoridades daquele país estão atentas ao potencial econômico do setor criativo, e sinalizam certo esgotamento do modelo industrial tradicional. É interessante notar que os referidos centros situam-se, em números iguais, em Pequim, e em Hong Kong. A primeira cidade, juntamente com Xangai, é uma espécie de catedral da indústria, representando um modelo de desenvolvimento quase esgotado, de pouca ou nenhuma sustentabilidade ambiental, sede governamental de um país que, mesmo antes do regime comunista, já se caracterizava pelo seu fechamento em relação ao 
restante do mundo, excessivamente apegado às tradições e desconfortável em relação à livre circulação de idéias e de manifestações espontâneas de indivíduos. Hong Kong, ao contrário, há pouco mais de uma década ainda era governada pela Inglaterra, com imprensa livre, hábitos fortemente ocidentalizados, inclusive em relação a consumo de produtos em geral e, entre eles, produtos culturais e de entretenimento. Hong Kong, ou a SAR - Special Administrative Region, como é tratada pelo governo - representa uma espécie de ilha ocidental em território chinês e se contrapõe em muitos aspectos à cultura tradicional dominante. E o interessante é que em "ambas as Chinas", existe de maneira equânime a percepção do valor estratégico da economia criativa, como nos provam os referidos centros. Ainda em relação a Pequim, Chengyu (2008) explica que esta:

Resolveu desenvolver as indústrias culturais e criativas de maneira estratégica. Durante o $11^{\circ}$. Plano Qüinqüenal, Pequim investirá na construção das indústrias culturais e criativas, cujo valor excederá US\$13,3 bilhões em 2010, levando em conta o atual crescimento médio de $15,1 \%$. Caso se realize, representará mais de 10\% do PIB de Pequim." 20

Xangai, por sua vez, realiza a Expo Xangai. O evento, de proporções monumentais, tem foco na sustentabilidade urbana e inclusão social, onde a economia criativa cruza transversalmente todas as áreas. Em 2006, a cidade realizou uma pesquisa de avaliação do consumo de produtos de natureza criativa; em seu 11․ Plano Qüinqüenal, a prefeitura incluiu as indústrias criativas como uma das questões-chave para o desenvolvimento da cidade; em 2007 a prefeitura lançou o documento "Key Guide for the Development of Creative Industries in Shanghai", estabelecendo suas áreas prioritárias de atuação. De acordo com a UNCTAD, as indústrias criativas são responsáveis por 7\% do PIB daquela cidade ${ }^{21}$.

\subsection{Brasil}

No Brasil, a economia criativa vem paulatinamente conquistando seu espaço junto ao setor público e à academia, cada vez mais interessados e conscientes do

\footnotetext{
20 Xiong Chengyu, em Tendências Atuais da Indústria Cultural Chinesa, inserido em Fonseca Reis, A. C. (organização) (2008) Economia Criativa Como Estratégia de Desenvolvimento: Uma Visão dos Países em Desenvolvimento (São Paulo: Editora Itaú Cultural) (página 228)

21 UNCTAD (2008) The Creative Economy Report (pág. 181) [http://www.unctad.org/en/docs/ditc20082cer_en.pdf]
} 
Economia criativa: uma visão global

potencial econômico e social que o setor tem a oferecer. Também começam a se articular entidades setoriais, ONGs, fundações e empresas privadas, profissionais e empreendedores criativos, de maneira geral, se mobilizando em redes de debates e intercâmbio, elaborando e desenvolvendo projetos de pesquisa e de ação. A insofismável constatação do avanço e do potencial econômico desse setor impõe a devida atenção da sociedade, que tem se organizado, ainda que embrionariamente, para as oportunidades que ele representa. Desde 2009, o Ministério da Cultura incorporou à sua estrutura uma coordenação exclusivamente dedicada à economia da cultura. Documento recentemente emitido pelo Ministério22 aponta que:

O Brasil tem importantes diferenciais competitivos nesse setor [economia da cultura]: 1. a facilidade de absorção de novas tecnologias; 2. a criatividade e a vocação para inovação; 3 . a disponibilidade de profissionais de alto nível em todos os segmentos da produção cultural."

E prossegue:

"Atuam no país 320 mil empresas voltadas à produção cultural, que geram 1,6 milhão de empregos formais. Ou seja, as empresas da cultura representam 5,7\% do total de empresas do país e são responsáveis por $4 \%$ dos postos de trabalho."

(...) “O salário médio mensal pago pelo setor da cultura é de 5,1 salários mínimos, equivalente à média da indústria, e $47 \%$ superior à média nacional."

Numa ação conjunta entre o Ministério da Cultura e o Instituto Brasileiro de Geografia e Estatística (IBGE), foi realizada a pesquisa que gerou o Sistema de Informações e Indicadores Culturais ${ }^{23}$ num trabalho pioneiro, visando o estabelecimento de um quadro estatístico setorial e avaliando o seu peso econômico e social no desenvolvimento brasileiro. Este trabalho é desbravador e deverá ter desdobramentos em etapas futuras, possivelmente com ajustes para o

22 Porta, P. (Ministério da Cultura / PRODEC) Economia da Cultura - Um Setor Estratégico para o País [http://www.cultura.gov.br/site/wp-content/uploads/2008/04/texto-sobre-oprodec-paula-porta.pdf]

${ }^{23}$ Ministério da Cultura / IBGE - Sistema de Informações e Indicadores Culturais (2003 2005),

[http://www.ibge.gov.br/home/estatistica/populacao/indic_culturais/2003/indic_culturais200 3.pdf] 
Alessandra Meleiro

Fábio Fonseca

enquadramento no SICSUR - Sistema de Informações Culturais do MERCOSUL. Como dados mais relevantes, podemos destacar que as indústrias culturais à época, empregavam $4 \%$ da força de trabalho e representavam 5,2\% das empresas brasileiras. O governo brasileiro tem despertado para o setor em diversas áreas do estado, e não apenas através do Ministério da Cultura. Podemos citar o Ministério do Turismo, que realiza o programa TBC - Turismo de Base Comunitária, em grande parte inspirado em indústrias criativas associadas ao turismo. A ABC Agência Brasileira de Cooperação, órgão ligado ao Ministério das Relações Exteriores, que possui uma estrutura dedicada à cooperação na área de economia criativa, especialmente com países africanos e da CPLP. O Ministério do Desenvolvimento, Indústria e Comércio, através de sua Secretaria de Inovação, enviou recentemente uma delegação à Europa, com o objetivo de conhecer de perto as principais experiências de clusters do setor criativo.

Diversas universidades têm aberto áreas de pesquisa em seus programas de graduação e pós-graduação. Como exemplos importantes, temos a USP, a UNICAMP, a UFRJ, a Universidade Cândido Mendes (RJ), a FGV (SP e RJ), a UFPE, UFF e UFBA, entre outras, que têm abrigado pesquisadores e fomentado a publicação de estudos e livros. Nesse particular, temos uma série de publicações que já compõem um pequeno arsenal teórico para embasar as ações, principalmente no setor público. Podemos citar o trabalho de pesquisadores como Ana Carla Fonseca Reis, Fábio Sá Earp, Lídia Goldenstein, Ana Jaguaribe, Paulo Miguez, Luiz Carlos Prestes Filho, etc.

Existem iniciativas em andamento em âmbito local. No Rio de Janeiro, por exemplo, está em fase de implantação o Pólo de Economia Criativa do Rio de Janeiro, o chamado PEC RIO. Trata-se de uma ação conjunta entre a Prefeitura, o Governo do Estado, a Pontifícia Universidade Católica do Rio de Janeiro (PUCRIO), através do Instituto Gênesis, a Federação das Indústrias do Rio de Janeiro (FIRJAN) e o Serviço Brasileiro de Apoio às Micro e Pequenas Empresas do Rio de Janeiro (SEBRAE/RJ). O PEC RIO será abrigado na zona portuária da cidade, uma área degradada que passa por um processo de regeneração urbana, sendo que o empreendimento é tido como uma peça importante nesse plano de revitalização. Iniciativa semelhante ao PEC RIO se inicia em Recife, sob a coordenação da UFPE.

Os principais atores do PEC RIO contam com áreas exclusivas dedicadas à economia criativa. A FIRJAN, por exemplo, foi a primeira entidade industrial brasileira a criar uma diretoria para o tema. Em 2006, a entidade publicou um trabalho intitulado "A Cadeia da Indústria Criativa no Brasil". ${ }^{24}$ Já o Instituto Gênesis, da PUC/RIO, além de uma coordenação exclusiva, promove incubação de

${ }^{24}$ FIRJAN (2008) Estudos para o Desenvolvimento do Estado do Rio de Janeiro (No. 2) A Cadeia da Indústria $\quad$ Criativa $\quad$ no Brasil [http://www.firjan.org.br/data/pages/2C908CE9215B0DC40121685C72026F2E.htm] 
Economia criativa: uma visão global

negócios de lastro criativo, com ênfase em tecnologia. A Secretaria de Cultura do Estado conta com uma Coordenação de Indústrias Criativas e assim por diante. Em 2006, o BNDES criou o seu Departamento de Economia da Cultura, que resultou na habilitação do "Programa BNDES para o Desenvolvimento da Economia da Cultura"25, ampliando o financiamento para cinco segmentos considerados estratégicos, a saber: mercado editorial e de livrarias, patrimônio cultural, mercado fonográfico, espetáculos ao vivo e audiovisual.

Apesar de programas como esse, ainda é tímida a participação do estado no fomento ao setor, que apresenta uma grande perspectiva de retorno de investimento. Em meados dos anos de 1990, a Fundação João Pinheiro realizou um estudo que apontava que as indústrias culturais eram capazes de gerar 160 postos de trabalho para cada 1 milhão de reais investidos ${ }^{26}$, resultado maior, por exemplo, que a indústria da construção civil e do turismo. Uma pesquisa realizada pela Pricewaterhousecoopers projeta um impressionante salto na economia cultural mundial, que, em 2005, era responsável por U\$1,3 trilhão e deverá atingir U $\$ 1,8$ trilhão em 2010, representando uma média de crescimento de 6,6\% ao ano ${ }^{27}$.

Algo que tem caracterizado o ambiente para o setor, no Brasil, é o excesso de debate em contraposição à carência de ações concretas. Como vimos, muito tem sido discutido; instituições e estruturas têm sido criadas; são feitas pesquisas; promovem-se fóruns, congressos e seminários diversos etc. Porém, de maneira prática, a maior parte das iniciativas, de fato, econômicas, ou seja, os empreendimentos criativos em si, continuam sendo produzidas basicamente fora do que seria um guarda-chuva estratégico provido pelo estado, estimulando os atores sociais através de programas regulares de capacitação, financiamento, criação de um ambiente favorável, mitigando os riscos de negócios, entre outras ações. É fundamental a participação do Estado brasileiro para gerar o impulso capaz de elevar a economia criativa a um estágio em que essa possa realizar todo o seu potencial socioeconômico e trazer os retornos que, consensualmente, se crê que ela seja capaz de prover. Enquanto isso não acontece, vemos uma intensa concentração de bens e serviços culturais importados pelo Brasil. Hoje, mais de $45 \%$ de tudo o que se consome em termos de bens e serviços culturais são importados dos Estados Unidos e do Reino Unido, contrastando com os $21 \%$ que se percebe na América Latina e no Caribe ${ }^{28}$.

${ }^{25}$ http://www.bndes.gov.br/SiteBNDES/bndes/bndes_pt/Areas_de_Atuacao/Cultura/Procult/ index.html

${ }^{26}$ Fundação João Pinheiro (1998) Diagnóstico dos Investimentos em Cultura No Brasil volume 3 (páginas 13 e 43)

27 PriceWaterhouseCoopers - Global Entertainment and Media Outlook 2006 - 2010

${ }^{28}$ Fonseca Reis, A. C. (2008) Economia Criativa Como Estratégia de Desenvolvimento: Uma Visão dos Países em Desenvolvimento (Ed. Itaú Cultural, São Paulo) (página 129) [http://www.garimpodesolucoes.com.br/downloads/ebook_br.pdf] 
Alessandra Meleiro

Fábio Fonseca

\section{Economia criativa: mas, afinal, o que é isso?}

\subsection{Principais conceitos envolvidos}

A economia criativa não é um objeto de estudo recente da economia. A partir do final dos anos de 1990, no entanto, ela vem sendo mais profundamente estudada e se configurando numa alternativa concreta de estratégia para desenvolvimento. Podemos estabelecer como um marco recente a emissão do documento australiano ${ }^{29}$ de 1994, onde figura, pela primeira vez, o conceito de Nação Criativa, que visava à construção de uma plataforma para uma política cultural inovadora alçando o tema à condição de setor estratégico. Cada vez mais, a economia criativa conquista espaço nas agendas econômicas, políticas e acadêmicas. Sob diversos nomes, tais como economia da cultura, indústrias criativas, economia do intangível, economia imaterial ou nova economia, só para citar alguns, ela se faz presente nas estruturas de governança, desde o plano local ao internacional. Esses diversos conceitos expressam níveis de abrangência diferentes - com distinções freqüentemente sutis - entre as perspectivas de compreensão possíveis, o que pode ser considerado natural, dado o seu estágio de maturação. No entanto, todos gravitam em torno de uma idéia central, qual seja, o desenvolvimento de uma economia com lastro na cultura, na criatividade, nos valores humanos, nos saberes tradicionais, adepta da pluralidade e mais respeitosa com o meio ambiente.

\subsection{Indústria cultural}

O termo indústria cultural surgiu no pós-guerra, como crítica ferina ao fenômeno recente do entretenimento de massa. Foi cunhado por seus críticos, basicamente oriundos da Escola de Frankfurt ${ }^{30}$, com o objetivo de gerar impacto pelo discurso que associava no conceito duas palavras cujos conteúdos aparentemente ocupavam campos de significação muito distintos, até mesmo opostos. Mais recentemente, parece haver uma aceitação mais tranqüila de que as indústrias culturais são simplesmente aquelas que produzem bens e serviços culturais. Pela definição da UNESCO, são as indústrias que "combinam a criação, produção e comercialização de conteúdos que são de natureza cultural e

${ }^{29}$ Creative Nation: Commonwealth Cultural Policy, Outubro de 1994 (Camberra, Austrália) [http://www.nla.gov.au/creative.nation/contents.html]

${ }^{30}$ Escola de pensamento formada por revisionistas neo-marxistas, inicialmente abrigados no Instituto de Pesquisa Social, da Universidade de Frankfurt. 
Economia criativa: uma visão global

intangível. Esses conteúdos são tipicamente protegidos por copyright e assumem a forma de bens e serviços."

\subsection{Economia da Cultura}

A economia da cultura é a definição atribuída à aplicação da economia analítica, equipada com suas ferramentas e metodologias, sobre as artes criativas e performáticas, patrimônio e herança cultural, bem como as chamadas indústrias culturais. Sua atenção está voltada para a organização econômica do setor cultural, compreendendo a participação de todos os atores envolvidos, como artistas, produtores, consumidores, governos etc. É fruto do crescente interesse dos economistas, que cada vez mais compreendem a importância da cultura como potencial geradora de valor na sociedade do conhecimento.

\subsection{Indústrias Criativas}

A expressão indústrias criativas também foi usada pela primeira vez na publicação "Creative Nation", supracitada. Mais tarde, teve grande amplificação com a sua adoção pelo Reino Unido, quando da assunção ao poder do Partido Trabalhista, liderado por Tony Blair. Através do Departamento de Cultura, Mídia e Esporte $^{31}$, órgão do Ministério das Indústrias Criativas e Turismo, foi constituída uma força tarefa com vistas ao fomento desse segmento econômico. Na definição do Creative Clusters ${ }^{32}$, as indústrias criativas "are based on individuals with creative and arts skills, in alliance with managers and technologists, making marketable products, whose economic value lies in their cultural (or "intellectual") properties." Por esta perspectiva, as indústrias criativas alargam o campo de visão para além do grupo nuclear das atividades artísticas e culturais, bem como da indústria cultural, passando a incluir atividades funcionais que se desenvolvem tendo a criatividade como matéria-prima, tais como o design, a arquitetura, a criação de softwares de entretenimento, entre outros. Existem vários modelos esquemáticos de indústrias criativas. A UNCTAD ${ }^{33}$ considera quatro deles os mais significantes. A saber:

Modelo DCMS (Reino Unido)

\footnotetext{
${ }^{31}$ Department for Culture, Media and Sport [http://www.culture.gov.uk]

${ }^{32} \mathrm{http}: / / \mathrm{www}$. creativeclusters.com

33 UNCTAD (2008) The Creative Economy Report (pág.

[http://www.unctad.org/en/docs/ditc20082cer_en.pdf]
} 
Alessandra Meleiro

Fábio Fonseca

Segundo o modelo DCMS 34 , adotado no Reino Unido pelo Departamento de Cultura, Mídia e Esporte, indústrias criativas são definidas como aquelas que requerem criatividade, habilidade e talento, com potencial para criação de emprego e bem-estar, através da exploração de seu propriedade intelectual. Ele contempla 13 atividades consideradas estratégicas pelo governo.

\section{Modelo dos Textos Simbólicos}

É uma abordagem que considera que as artes tradicionais ("elevadas" ou "sérias") normalmente já são objeto de cuidado do establishment social e político, daí porque o modelo foca a sua atenção na cultura popular, a qual frequentemente se manifesta através da produção industrial, disseminação e consumo de textos e mensagens simbólicas, como as do cinema, da TV e da imprensa.

\section{Modelo dos Círculos Concêntricos}

O Modelo dos Círculos Concêntricos tem como pressuposto básico a assunção de que é o valor cultural dos bens culturais que provê essa indústria de sua característica mais distintiva. Assim, quanto mais evidente esse conteúdo cultural contido no produto ou serviço, mais forte é o seu apelo à produção industrial. Por essa premissa, esquematicamente se tem um núcleo de atividades essencialmente artísticas, manifestas em sons, textos e imagens, rodeado por círculos que contém atividades derivadas das atividades nucleares, os círculos concêntricos, sendo que o conteúdo cultural decresce à medida que o círculo se afasta do núcleo. O núcleo das artes é imediatamente circundado pelas atividades da indústria de produção puramente cultural (cinema, música, livros etc.), seguido pelo círculo da indústria e atividade criativa (arquitetura, propaganda etc.), fechando com o círculo da indústria criativa relacionada, que é composto por um conjunto mais amplo de atividades industriais cujos produtos possuem muito trabalho criativo agregado, como, por exemplo, a indústria de softwares e de celulares. Este foi o modelo utilizado pela Comissão Européia na elaboração do estudo The Economy of Culture in Europe, supracitado.

\footnotetext{
${ }^{34}$ Department For Culture, Media and Sport (órgão do Ministério das Indústrias Criativas e
} do Turismo do Reino Unido) 
Economia criativa: uma visão global

Figura 1. Modelo dos círculos concêntricos

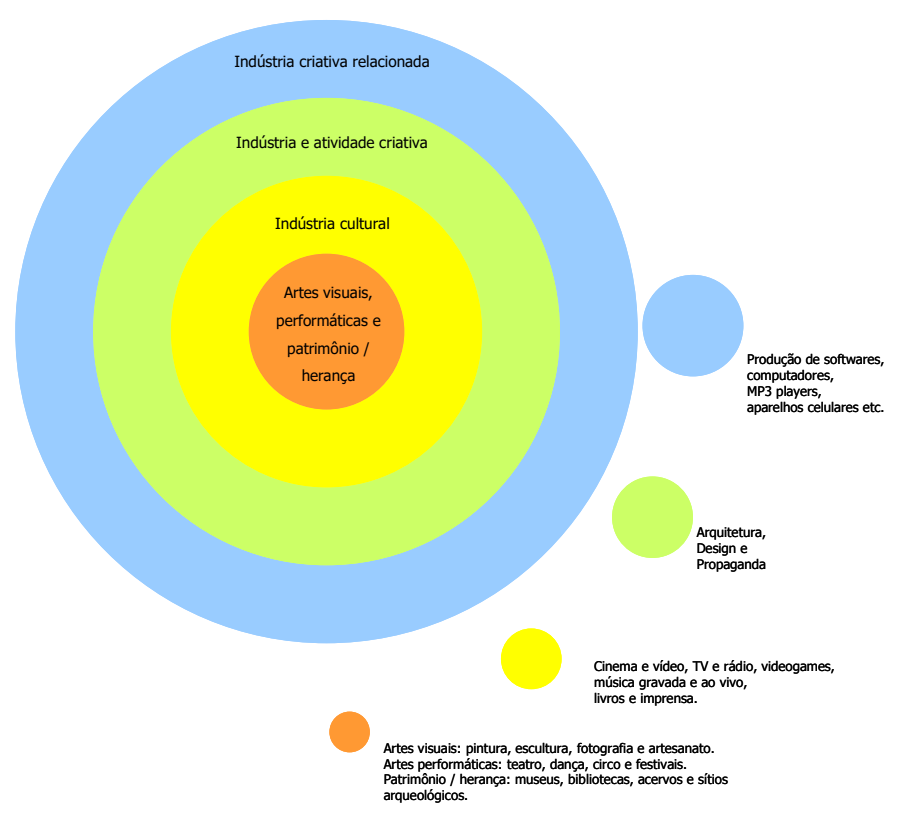

Modelo Copyright (OMPI5)

É o modelo baseado estritamente nas indústrias relacionadas com a criação, manufatura, produção, transmissão e distribuição de trabalhos protegidos por copyright, sendo que faz uma distinção entre as indústrias que de fato produzem propriedade intelectual e aquelas que atuam na entrega dos produtos e serviços aos consumidores finais.

A UNCTAD tem também sua própria visão. Segundo a Organização, que discutiu à exaustão o seu conceito de indústrias criativas, durante a sua $11^{\mathrm{a}}$. Conferência ${ }^{36}$, a criatividade em questão se expande para além das atividades de forte componente artístico, passando a ser qualquer atividade econômica que gere produtos simbólicos com forte sustentação na propriedade intelectual, com o mercado mais amplo possível.

35 Organização Mundial da Propriedade Intelectual (ou WIPO, na sigla em inglês).

${ }^{36}$ UNCTAD XI, São Paulo, 2004 - High Level Panel on Creative Industries and Development 
"The creative industries:

- $\quad$ are the cycles of creation, production and distribution of goods and services that use creativity and intellectual capital as primary inputs;

- constitute a set of knowledge-based activities, focused on but not limited to arts, potentially generating revenues from trade and intellectual property rights;

- $\quad$ comprise tangible products and intangible intellectual or artistic services with creative content, economic value and market objectives;

- $\quad$ are at the cross-road among the artisan, services and industrial sectors; and

- $\quad$ constitute a new dynamic sector in world trade." 37

Para sustentar seu conceito, propõe um modelo esquemático, segundo o qual as indústrias criativas se apresentam dispostas em quatro categorias formadas por oito blocos, algumas de áreas correlatas, que são: (a) categoria 1 (patrimônio cultural), contendo categoria de mesmo nome; (b) categoria 2 (artes), contendo as categorias "artes visuais" e "artes dramáticas"; (c) categoria 3 (mídia), abrangendo as categorias "edição e mídia impressa" e "audiovisual"; e (d) categoria 4 (criações funcionais), comportando "design", "novas mídias" e "serviços criativos".

\footnotetext{
37 UNCTAD (2008) The Creative Economy Report (pág. [http://www.unctad.org/en/docs/ditc20082cer_en.pdf]
} 


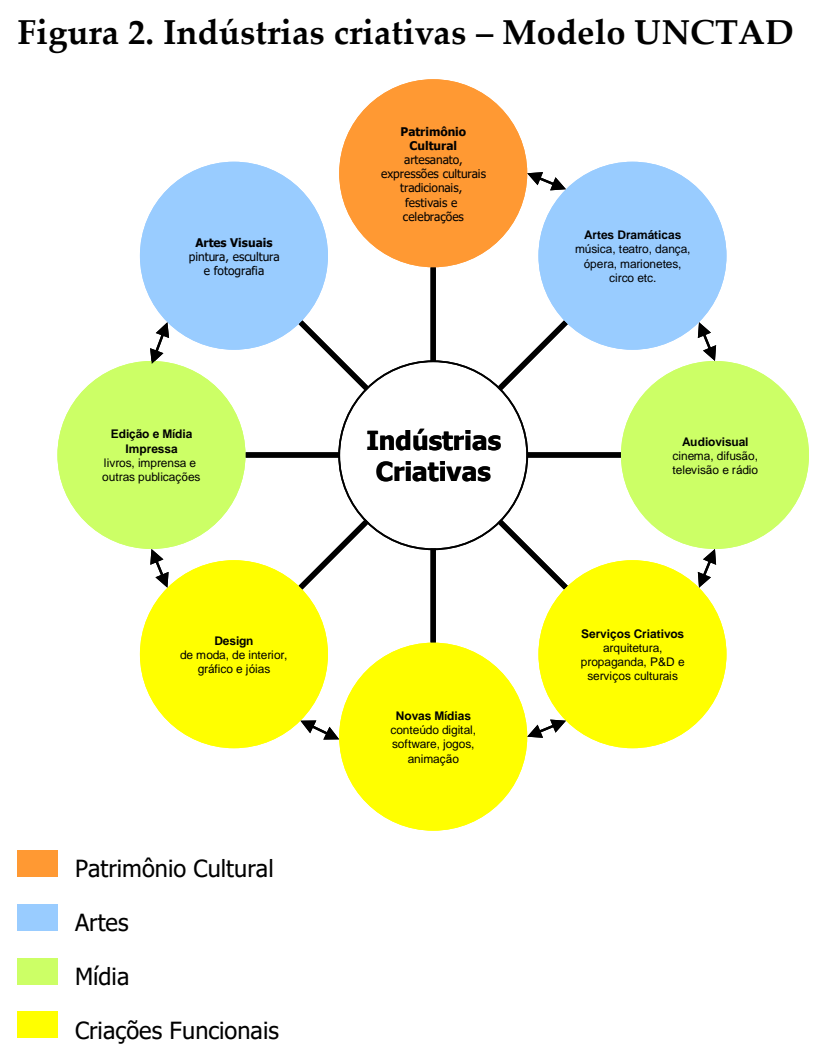

\subsection{Economia Criativa}

Certamente, o mais amplo de todos os conceitos em questão, o conceito de economia criativa foi cunhado por John Howkins ${ }^{38}$, que apresenta, como novidade, a forma como criatividade e economia se combinam numa nova relação, em natureza e extensão, a partir da qual se prestam a um extraordinário potencial de geração de valor e bem-estar. Em seu Creative Economy Report, 2008, a UNCTAD apresenta, de maneira sumarizada, sua definição de economia criativa, conforme se segue:

"The 'creative economy' is an evolving concept based on creative assets potentially generating economic growth and development.

- It can foster income generation, job creation and export earnings while promoting social inclusion, cultural diversity and human development.

${ }^{38}$ Howkins, J. (2001) The Creative Economy: How People Make Money from Ideas 
Alessandra Meleiro

Fábio Fonseca

- It embraces economic, cultural and social aspects interacting with technology, intellectual property and tourism objectives.

- It is a set of knowledge-based economic activities with a development dimension and crosscutting linkages at macro and micro levels to overall economy.

- $\quad$ It is a feasible development option calling for innovative, multidisciplinary policy responses and interministerial action.

- $\quad$ At the heart of the creative economy are the creative industries."

A abrangência do conceito de economia criativa o torna mais facilmente aceito em diversos segmentos da sociedade, aumentando a percepção do tema como um objeto de estudo a ser considerado ainda mais seriamente.

\section{Considerações finais}

A economia criativa é inegavelmente tema de grande interesse internacional, sendo objeto de políticas públicas em países de todas as regiões do globo, independentemente dos estágios de desenvolvimento em que se encontram tais nações. As quase duas décadas em que a economia criativa tem inserção sistemática nas agendas públicas mostram que não se trata de uma 'tendência', mas de realidades regionais que se encontram em distintos estágios de maturação. A despeito de todo o potencial da economia criativa como alavanca para o desenvolvimento econômico e social, o que é largamente reconhecido, é fato que muitos países têm dificuldade na realização de seu potencial. A implementação de "políticas criativas" (em apoio às indústrias criativas e cidades criativas) em diferentes cidades e regiões de todo o mundo tem levado a questionamentos com relação à aplicabilidade destas intervenções em diferentes contextos locais, regionais e nacionais. Mais especificamente falando, políticas criativas geradas em países desenvolvidos podem ser transferidas ao contexto sul americano, e viceversa? Quais são os desafios e dificuldades em definir e dimensionar as indústrias criativas na América do Sul, em comparação com o Reino Unido e outros países desenvolvidos? Como estes desafios e oportunidades para o desenvolvimento das indústrias criativas do hemisfério Sul são tratados por cidades e regiões específicas, e como poderiam ser incorporados às políticas públicas, levando-se em conta necessidades e contextos específicos? 
Economia criativa: uma visão global

\section{Referências}

UNCTAD (2008) Creative Economy Report - The Challenge of Assessing the

Creative Economy: Towards Informed Policy-making [http://www.unctad.org/en/docs/ditc20082cer_en.pdf]

PNUD (2004) Relatório do Desenvolvimento Humano - Liberdade Cultural num Mundo Diversificado [http://www.pnud.org.br/rdh/]

D'ALMEIDA, F. e ALLEMAN M. E. (2004) Les Industries Culturelles Des Pays Du Sud

[http://www.francophonie.org/IMG/pdf/Industries_cult._pays_du_sud_2004.pdf]

MIGUEZ, P. (2007) Repertório de Fontes Sobre Economia Criativa [http://www.cult.ufba.br/arquivos/repertorio_economia_criativa.pdf]

Howkins, J. (2005) Enhancing The Creative Economy - Shaping an International Centre on Creative Industries (Salvador)

CASTRO LIMA, C. L. (2005) Debate Sobre Indústrias Criativas: Uma Primeira Aproximação Para 0 Estado da Bahia [http://www.mesteco.ufba.br/scripts/arquivos/at_ecobai_06.pdf]

SÁ EARP, F. (Organização) (2002) Pão e Circo: Fronteiras e Perspectivas da Economia do Entretenimento. (Rio de Janeiro: Palavra e Imagem)

Chandavarkar, N. (2005) Building Socially-Inclusive Creative Economies: The Case For An International Institution

UNCTAD Secretariat, com contribuição de Jaguaribe, A. (2005) Setting The Institutional Parameters of the International Centre on Creative Industries (ICCI) (documento não-oficial)

FONSECA REIS, A. C. (Organização) (2008) Economia Criativa Como Estratégia de Desenvolvimento: Uma Visão dos Países em Desenvolvimento - São Paulo - Itaú Cultural

[http://www.garimpodesolucoes.com.br/downloads/ebook_br.pdf]

FONSECA REIS, A. C e Deheinzelin, L (2005) Centro Internacional de Economia Criativa - CIEC: Documento Referência / Constituição Comitê Deliberativo

COMMONWEALTH (1994) Creative Nation: Commonwealth Cultural Policy, Canberra [http://www.nla.gov.au/creative.nation/contents.html]

GORDON, J.C. e BEILBY-ORRIN, H. (2007) International Measurement of the Economic and Social Importance of Culture - (OCDE, Paris) [http://www.oecd.org/dataoecd/26/51/37257281.pdf]

KEA European Affairs (2006) The Economy of culture in Europe [http://www.keanet.eu/ecoculture/studynew.pdf]

UIS UNESCO Institute for Statistics - International Flows of Selected Cultural Goods and Services, 1994-2003 - Defining and Capturing the Flows of Global 
Alessandra Meleiro

Fábio Fonseca

Cultural

Trade

(Montreal,

[http://www.uis.unesco.org/template/pdf/cscl/IntlFlows_EN.pdf]

Pol, H. van der - UIS - UNESCO Institute for Statistics - Measurement Issues in

Relation to Cultural Statistics (Istanbul, 2007)

[http://www2.dpt.gov.tr/oecd_ing/topkapi_a/29June2007/9.00-

10.30/Hendrik\%20pol_-Istanbul-2007_2.ppt]

Gorgulho, L. F., Goldenstein, M., Machado Alexandre, P. V., Taboas de Mello, G. A. (2007) A Economia da Cultura, o BNDES e o Desenvolvimento Sustentável [http://www.bndes.gov.br/SiteBNDES/export/sites/default/bndes_pt/Galerias/Arqu ivos/conhecimento/bnset/set3007.pdf]

GLA Economics (2004) London's Creative Sector: 2004 Update [http://www.planotecnologico.pt/document/london_creative_sector_2004.pdf]

Porta, P. (Ministério da Cultura / PRODEC) Economia da Cultura - Um Setor

Estratégico para o País [http://www.cultura.gov.br/site/wpcontent/uploads/2008/04/texto-sobre-o-prodec-paula-porta.pdf]

Ministério da Cultura / IBGE - Sistema de Informações e Indicadores Culturais (2003

[http://www.ibge.gov.br/home/estatistica/populacao/indic_culturais/2003/indic_cul turais2003.pdf]

FIRJAN (2008) Estudos para o Desenvolvimento do Estado do Rio de Janeiro (No.

2) A Cadeia da Indústria Criativa no Brasil
[http://www.firjan.org.br/data/pages/2C908CE9215B0DC40121685C72026F2E.htm] Fundação João Pinheiro (1998) Diagnóstico dos Investimentos em Cultura No Brasil - volume 3

PriceWaterhouseCoopers - Global Entertainment and Media Outlook 2006 - 2010 Sá Earp, F. e Kornis, G. (2005) A Economia da Cadeia Produtiva do Livro (Rio de Janeiro: BNDES). 